\title{
A transparent Pyrex -reactor for combined in situ optical characterization and photocatalytic reactivity measurements.
}

Dionigi, Fabio; Nielsen, Morten Godtfred; Pedersen, Thomas; Hansen, Ole; Chorkendorff, Ib; Vesborg, Peter Christian Kjærgaard

Published in:

Review of Scientific Instruments

Link to article, DOI:

$10.1063 / 1.4826495$

Publication date:

2013

Document Version

Publisher's PDF, also known as Version of record

Link back to DTU Orbit

Citation (APA):

Dionigi, F., Nielsen, M. G., Pedersen, T., Hansen, O., Chorkendorff, I., \& Vesborg, P. C. K. (2013). A transparent Pyrex -reactor for combined in situ optical characterization and photocatalytic reactivity measurements. Review of Scientific Instruments, 84(10), [103910]. https://doi.org/10.1063/1.4826495

\section{General rights}

Copyright and moral rights for the publications made accessible in the public portal are retained by the authors and/or other copyright owners and it is a condition of accessing publications that users recognise and abide by the legal requirements associated with these rights.

- Users may download and print one copy of any publication from the public portal for the purpose of private study or research.

- You may not further distribute the material or use it for any profit-making activity or commercial gain

- You may freely distribute the URL identifying the publication in the public portal 


\section{AIP $\mid \begin{aligned} & \text { Review of } \\ & \text { Scientifi Instruments }\end{aligned}$}

\section{A transparent Pyrex -reactor for combined in situ optical characterization and photocatalytic reactivity measurements}

F. Dionigi, M. G. Nielsen, T. Pedersen, O. Hansen, I. Chorkendorff, and P. C. K. Vesborg

Citation: Review of Scientific Instruments 84, 103910 (2013); doi: 10.1063/1.4826495

View online: http://dx.doi.org/10.1063/1.4826495

View Table of Contents: http://scitation.aip.org/content/aip/journal/rsi/84/10?ver=pdfcov

Published by the AIP Publishing

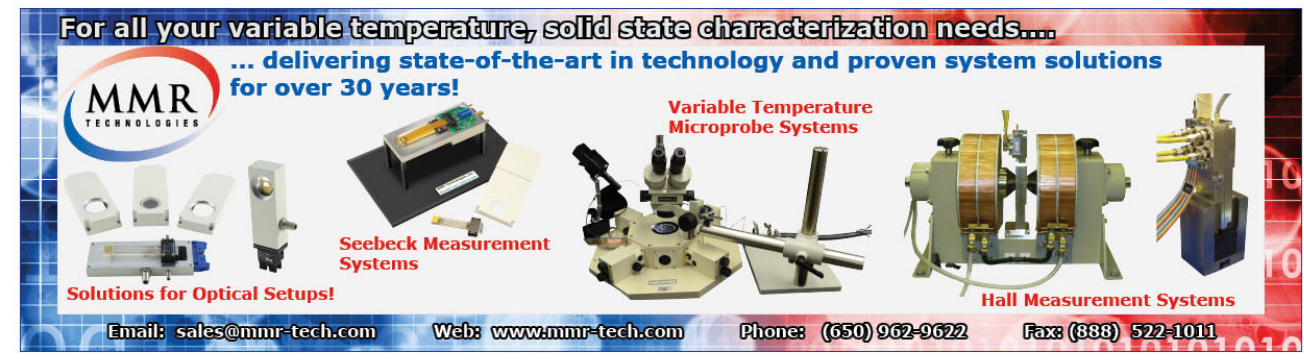




\title{
A transparent Pyrex $\mu$-reactor for combined in situ optical characterization and photocatalytic reactivity measurements
}

\author{
F. Dionigi, ${ }^{1,2}$ M. G. Nielsen, ${ }^{1}$ T. Pedersen, ${ }^{2}$ O. Hansen,,${ }^{1,2}$ I. Chorkendorff, ${ }^{1}$ \\ and P. C. K. Vesborg ${ }^{1, a)}$ \\ ${ }^{1}$ CINF, Department of Physics, Building 312, Fysikvej, Technical University of Denmark, DTU, \\ DK-2800 Kgs. Lyngby, Denmark \\ ${ }^{2}$ Department of Micro- and Nanotechnology, Nanotech, Building 345 East, Technical University of Denmark, \\ DTU, DK-2800 Kgs. Lyngby, Denmark
}

(Received 12 August 2013; accepted 8 October 2013; published online 30 October 2013)

\begin{abstract}
A new Pyrex-based $\mu$-reactor for photocatalytic and optical characterization experiments is presented. The reactor chamber and gas channels are microfabricated in a thin poly-silicon coated Pyrex chip that is sealed with a Pyrex lid by anodic bonding. The device is transparent to light in the UV-visnear infrared range of wavelengths (photon energies between $\sim 0.4$ and $\sim 4.1 \mathrm{eV}$ ). The absorbance of a photocatalytic film obtained with a light transmission measurement during a photocatalytic reaction is presented as a proof of concept of a photocatalytic reactivity measurement combined with in situ optical characterization. Diffuse reflectance measurements of highly scattering photocatalytic nanopowders in a sealed Pyrex $\mu$-reactor are also possible using an integrating sphere as shown in this work. These experiments prove that a photocatalyst can be characterized with optical techniques after a photocatalytic reaction without removing the material from the reactor. The catalyst deposited in the cylindrical reactor chamber can be illuminated from both top and bottom sides and an example of application of top and bottom illumination is presented. (C) 2013 AIP Publishing LLC. [http://dx.doi.org/10.1063/1.4826495]
\end{abstract}

\section{INTRODUCTION}

In recent years, it has become possible to study catalytic reactions employing reactors with characteristic dimensions in the micrometer range. ${ }^{1}$ These reactors are therefore called $\mu$-reactors and they can be fabricated using a range of different techniques. In particular our group has been involved in the development of silicon based $\mu$-reactors. ${ }^{2}$ Briefly, these reactors are made of two parts that are bonded together after deposition of the catalyst. The bottom part is obtained by dicing a $20 \times 16 \mathrm{~mm}$ chip area from a micro-machined standard silicon wafer, while the top part is a Pyrex lid of the same dimensions. With these dimensions, up to 16 chips are fabricated from a single 4 in. wafer. The silicon chips are micromachined using deep reactive ion etching (DRIE) in order to obtain the desired structure of the gas flow channels, a $240 \mathrm{nl}$ volume reactor chamber, and a capillary for direct interface to a quadrupole mass spectrometer (QMS). The fabrication of these structures with dimensions in the micrometer range justifies the name of $\mu$-reactor. The catalyst can be deposited in the reactor chamber or on the Pyrex lid, whereupon the two parts are pressed together and the sandwich device is anodically bonded to form a hermetic seal between the two parts of the reactor. ${ }^{3}$ After anodic bonding, the reactor is ready for use. These small plug flow reactors have several advantages compared to a standard reactor with a chamber of several $\mathrm{ml}$ of volume. The small volume of the reactor chamber combined with a limiting flow capillary connected to a QMS makes it possible to perform fast time resolved measurements with a

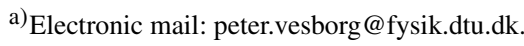

resolution on the order of a few seconds $(\sim 3 \mathrm{~s}$ in the $54 \mu \mathrm{m}$ wide capillary design). Furthermore, the small chamber allows high sensitivity measurements that require only a small amount of catalyst (typical reactor loadings are 20-60 $\mu \mathrm{g}$ ) to be carried out. ${ }^{4} \mathrm{~A}$ small reactor volume is also desirable if potentially dangerous reactions need to be performed. Due to these benefits, the transparency of the lid in the UV-visible range of wavelengths and the thermal properties of the reactor that can withstand temperatures as high as $500{ }^{\circ} \mathrm{C}$ (close to the Pyrex softening point of $820^{\circ} \mathrm{C}$ ), these reactors are useful tools to study both photocatalytic and thermal catalytic reactions. Regarding photocatalysis, oxidation reactions (of carbon monoxide, methane, methanol, etc. $)^{5}$ and overall water splitting ${ }^{6,7}$ have been studied, also fundamental photocatalytic mechanisms have been investigated. ${ }^{8}$ All of the studies mentioned were carried out with our standard silicon based $\mu$-reactor and the reaction products and activity were measured with a QMS.

Unfortunately, despite its numerous advantages, the silicon based $\mu$-reactor has one main limitation: once it has been sealed, it is not possible to reopen the reactor unless the chip is destroyed (even though it is possible to break the chip without destroying the area where the catalyst is deposited). Therefore, no in situ techniques or characterization in between different activity measurements can be performed with the technology employed so far. It was only possible to obtain information on the catalyst material before the bonding of the reactors. These limitations are overcome with the transparent $\mu$-reactor presented here. With this new device, it is possible to use optical characterization techniques based on irradiation and detection of photons with wavelength in the 
UV-vis-NIR (near infrared) range (photon energies between $\sim 0.4$ and $\sim 4.1 \mathrm{eV}$ ) both in transmission and reflection mode. These techniques can be performed on a sealed reactor, combining them with the detection of products of catalytic and photocatalytic reactions with sensitivity similar to that of the silicon based $\mu$-reactor. The status of a photocatalyst can be monitored optically and controlled at any moment if necessary and the risk of contamination is eliminated, since the sample does not need to be transferred to another system for characterization.

Hence any correlation between the results of activity measurements and optical characterizations are more solid, since the material and experimental conditions are unaltered.

The reactor proposed in this article also opens the possibility to more simply investigate fundamental mechanisms of photocatalysis that would otherwise involve a larger number of standard silicon based $\mu$-reactors and a higher uncertainty in the results of the measurements. This is possible due to the fact that a photocatalytic film can be illuminated from both sides using one single reactor.

\section{FABRICATION}

The fabrication process begins by growing a thin polycrystalline silicon layer (200 $\mathrm{nm}$ thick) in a low pressure chemical vapor deposition process (LPCVD) on both sides of a Pyrex wafer by pyrolysis of $\mathrm{SiH}_{4}$ at $\sim 600{ }^{\circ} \mathrm{C}$ (Fig. 1(a)). Using standard UV photolithography the gas channel system is formed in a photoresist layer on one side of the wafer and the through holes are formed in a photoresist layer on the other side (Fig. 1(b)). The exposed poly-silicon is then etched in a $\mathrm{CF}_{4} / \mathrm{O}_{2}$ plasma and the resist layers are removed (Fig. 1(c)).

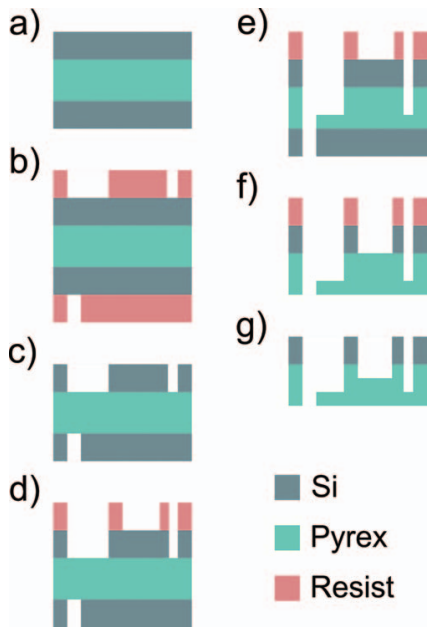

FIG. 1. Fabrication sequence for the poly-silicon coated Pyrex chip. The Pyrex wafer is coated with a thin poly-silicon layer on both sides (a). Two photoresist layers are applied with pattern for the channels system and the gas inlet and outlet holes (b). The silicon is etched in a $\mathrm{CF}_{4} / \mathrm{O}_{2}$ plasma and the resist layers are removed (c). Another photoresist layer is applied and patterned with both the reactor chamber structure and the gas channel system (d). The deep gas channels and holes are etched in the Pyrex and through the entire thickness of the wafer, respectively, using HF (e). The poly-Si is etched in a $\mathrm{HNO}_{3}: \mathrm{BHF}: \mathrm{H}_{2} \mathrm{O}$ solution (f). The Pyrex is then etched in $\mathrm{HF}$ to etch the reactor chamber and capillary to a depth of about $3.5 \mu \mathrm{m}$ and the remaining photoresist layer is removed in an oxygen plasma $(\mathrm{g})$.
Another photoresist layer is applied and patterned on the gas channel side and it is hard baked at $250{ }^{\circ} \mathrm{C}$. This layer holds both the reactor chamber structure and the gas channel system (Fig. 1(d)). The wafer is then submerged in $40 \% \mathrm{HF}$ for about 90 min to etch the deep gas channels in the Pyrex and holes through the entire thickness of the wafer for the gas inand outlets utilizing the poly-Si mask defined in the previous lithography step (Fig. 1(e)). Subsequently, the photoresist layer still in place is used as a mask to define the reactor chamber by etching the poly-Si in a $\mathrm{HNO}_{3}: \mathrm{BHF}: \mathrm{H}_{2} \mathrm{O}(20: 1: 20)$ solution (Fig. 1(f)). The silicon layer on the backside of the wafer is also etched away in this step. The Pyrex is then etched for $1 \mathrm{~min}$ in $40 \% \mathrm{HF}$ to etch the reactor chamber and capillary to a depth of about $3.5 \mu \mathrm{m}$, and finally the remaining photoresist layer is removed in an oxygen plasma (Fig. 1(g)). After etching, silicon will remain only in the places that are going to be sealed by anodic bonding to a Pyrex lid. This procedure leaves a reactor chamber which is fully transparent in transmission. The full transmission spectrum of the Pyrex lid from the UV to the infrared range is shown in Fig. 2. The spectrum is obtained combining two measurements performed with a UV-vis Cary 1E spectrometer and a Thermo Nicolet Nexus FTIR spectrometer.

Sixteen lids or reactors can be diced from a wafer, obtaining 16 reactors from two Pyrex wafers. The Pyrex lid without features has the dimensions of $20 \times 16 \mathrm{~mm}^{2}$, while the Pyrex lid with the poly-silicon layer and the etched structure is longer in one direction, measuring $21 \times 16 \mathrm{~mm}^{2}$.

The longer lid allows for direct contact to the poly-silicon layer during the anodic bonding process since a surface equal to $1 \times 16 \mathrm{~mm}^{2}$ of the poly-silicon remains uncovered by the Pyrex lid. The reason for this modification will be explained later, when discussing the bonding process.

A cross section schematic showing the structure of the final device is sketched in Fig. 3. The transparent $\mu$-reactor is a stacking structure of 3 layers, Pyrex/silicon/Pyrex, where the anodically bonded interface is drawn with a thick pink line

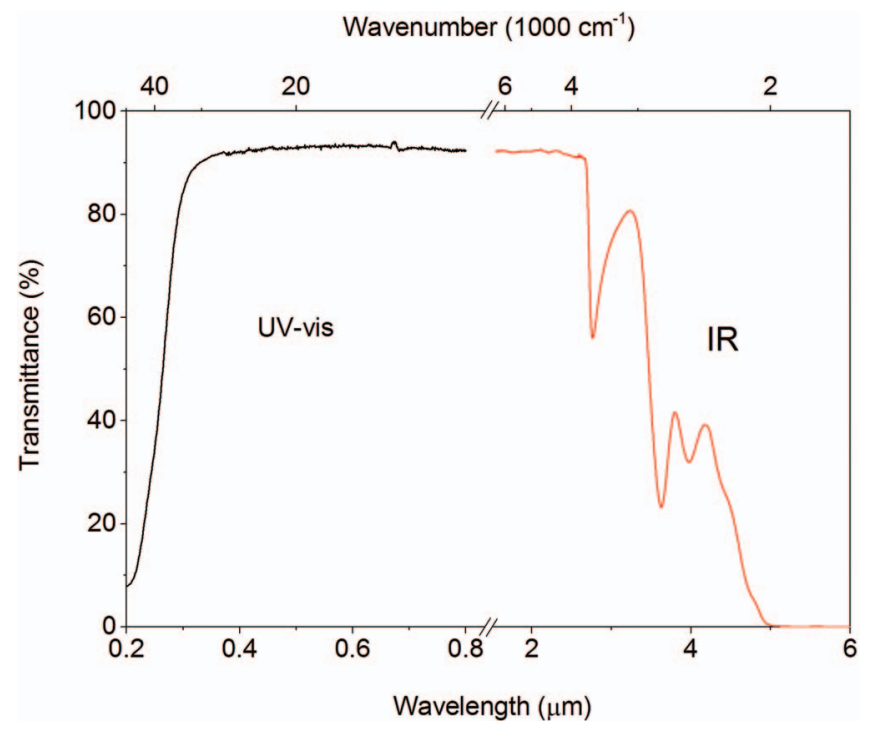

FIG. 2. UV-vis transmittance and IR transmittance of a $500 \mu \mathrm{m}$ thick Pyrex lid. 


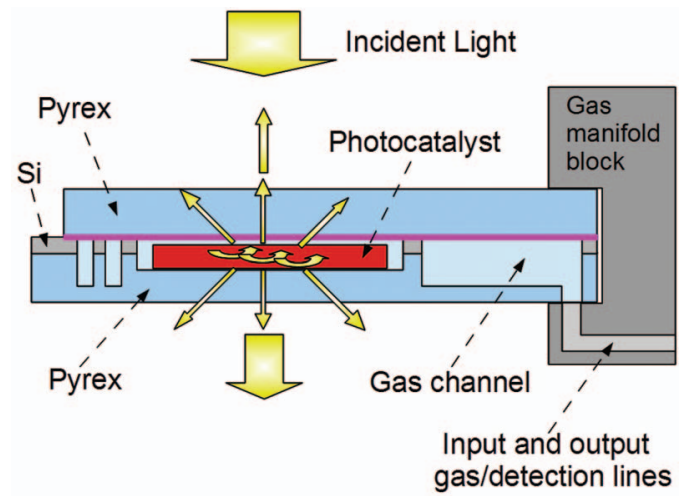

FIG. 3. Cross-section view of a transparent Pyrex $\mu$-reactor. The reactor is loaded with a photocatalyst and mounted on the gas manifold block. The schematic shows incident light illuminating the photocatalyst from the top. A small part of this light is reflected from the Pyrex lid. Most of the incident light passes through the top Pyrex lid and is absorbed or scattered in all directions by the photocatalytic nanoparticles or transmitted through the device. The anodically bonded Pyrex/silicon interface is drawn with a thick line (pink).

in Fig. 3. The total thickness is $\sim 1000 \mu \mathrm{m}$ (500 $\mu \mathrm{m}$ of Pyrex, $500 \mu \mathrm{m}$ of Pyrex, and $200 \mathrm{~nm}$ for the poly-silicon layer).

\section{DESIGN AND FEATURES}

Since the Pyrex is amorphous, the wet etch is isotropic. Consequently, it is difficult to obtain channels that are deep and narrow in contrast to the case of a silicon wafer, where the DRIE etch is anisotropic and high aspect ratios may be obtained. The reactor structure of the transparent Pyrex reactor is shown in the picture of the etched silicon-coated Pyrex chip in Fig. 4. The reactor has four holes etched through the entire Pyrex lid and the silicon itself. Two of them are used as gas inlets (I1 and I2) and two as outlets (O1 and O2). A gas $A$ that enters the chip in the first inlet hole (I1) flows into two channels that are connected with the short inlet channel of the second inlet hole (I2). In this way gas $B$ that is flowing in this channel is in contact with gas $A$ from both sides. With this design the diffusion length required for gas mixing is decreased because gas $B$ can diffuse on both sides into the flow of gas $A$ and hence mix in a shorter time.

Subsequently, the gas mixture enters a long channel and exits the chip from the first outlet hole (O1). The rate of the

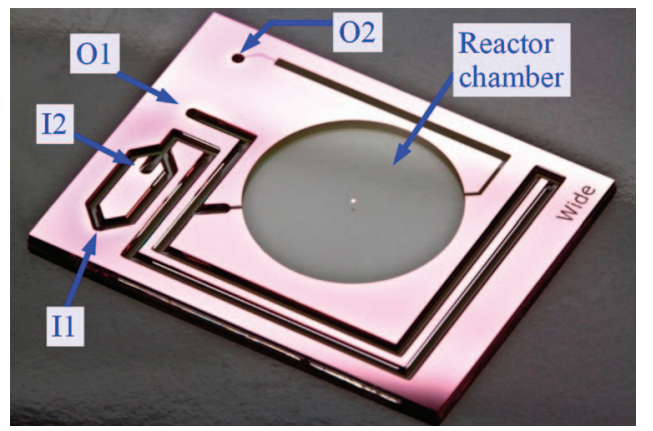

FIG. 4. Micromachined Pyrex chip with a thin silicon layer $(\sim 200 \mathrm{~nm})$ and the etched channel structures. A transparent Pyrex $\mu$-reactor is composed of this part anodically bonded to a Pyrex lid. flow entering the reactor and passing in this long channel is in the $\mathrm{ml} / \mathrm{min}$ range (typically between 1 and $30 \mathrm{ml} / \mathrm{min}$ ) and can be controlled with standard mass flow controllers (MFCs). The channel connecting the two input holes with $\mathrm{O} 1$ has been dimensioned to assure proper mixing on chip. Since the flow in the reactor is laminar (the Reynolds number is $\sim 25$ in case of air at $300 \mathrm{~K}, 1 \mathrm{bar}$, and a flow of $10 \mathrm{ml} / \mathrm{min}$ ), two gases can only mix by diffusion, which is a slow process.

The main part of the gas flow that enters the chip exits through $\mathrm{O} 1$ and flows in a gas line that is connected in series with a pressure controller. The total pressure in the reactor is set with this controller (in the range 0.1-3 bars).

A small part of the gas flow enters a channel branch connected to the reactor chamber. The chamber has the shape of a cylindrical cavity with the diameter of $1 \mathrm{~cm}$. A small pillar is left in the middle of the reactor volume in order to reduce the risk of collapse of the chamber during anodic bonding. The depth of the chamber is $3.7 \mu \mathrm{m}, 3.5 \mu \mathrm{m}$ etched in Pyrex, and $200 \mathrm{~nm}$ etched in silicon. Therefore, the total volume of the chamber is only $290 \mathrm{nl}$.

The chamber is connected with a channel and a capillary (length $\sim 1.9 \mathrm{~mm}$ ) to the second outlet hole (O2). The capillary serves to control the flow that enters the high vacuum chamber that hosts the QMS. Two different designs for the width of the capillary are available: $\sim 14 \mu \mathrm{m}$ and $\sim 63 \mu \mathrm{m}$. A flow of $\sim 1 \times 10^{16}$ molecules $\mathrm{s}^{-1}$ has been measured for a wide capillary transparent $\mu$-reactor at 1 bar, while the flow of the narrow capillary reactors is approximately five times less.

The reactor is mounted in a gas manifold block, described in a previous publication, ${ }^{2}$ by two screws and an aluminium bar. The bar presses the reactor against the manifold block and sealing is obtained using 4 Kalrez o-rings for the 4 inand outlet holes.

\section{SEALING BY ANODIC BONDING}

Anodic bonding fuses the Pyrex and silicon parts of the reactor together by heating the stack and applying a high electric field between the Pyrex (kept at negative potential) and the silicon. ${ }^{9}$ The two parts of the reactor are physically put in contact after deposition of a catalyst, and the reactor is placed on a hot plate at a temperature of $\sim 350^{\circ} \mathrm{C}$ (the anodic bonding setup is similar to the one in Ref. 3). During the bonding, the Pyrex lid coated with poly-silicon is facing the hot plate with the Pyrex side, while the silicon side is in contact with the other Pyrex lid. A metal mask is pressed against the top of the reactor by a metal tip that is connected to a power supply. In this way, a negative voltage of $\sim-1 \mathrm{kV}$ is applied to the top side of the reactor while the hot plate is electrically grounded. The mask covers most of the area of the Pyrex, apart from the circular area corresponding to the reactor chamber. The use of this mask is beneficial for the bonding since the time of the bonding is strongly decreased when the mask is used instead of a single point contact.

The thin silicon layer is grounded directly, by contacting it using a gold wire (a part of the silicon is not covered by the top Pyrex lid, see Fig. 3). The role of this extra contact is to increase the electric field in the region of the sealing between 
(a) $45^{\circ}$ Mirror

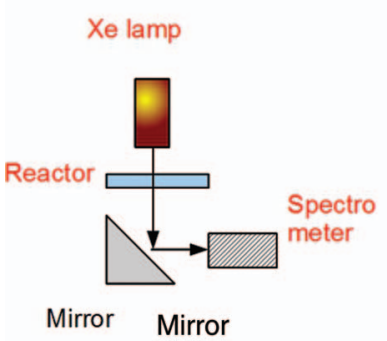

(b) Integrating Sphere

Xe lamp

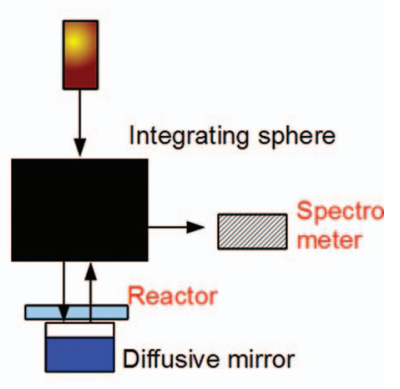

FIG. 5. Experimental setups for in situ UV-vis light transmission experiments (a) and diffuse reflectance measurements (b).

the silicon and the upper Pyrex lid. With this method a reactor can be bonded in approximately one hour.

The bonding method presented in this section demonstrates that it is possible to seal two Pyrex chips by anodic bonding using a thin poly-silicon interlayer of $\sim 200 \mathrm{~nm}$ of thickness.

\section{IN SITU OPTICAL CHARACTERIZATION SETUPS}

Two different configurations have been developed for measuring the absorbance and Kubelka-Munk function ${ }^{10}$ of a catalyst loaded in the Pyrex transparent reactor. These measurements have been chosen to show a proof of concept. Schematics of the two configurations are shown in Fig. 5.

The first configuration shown in Fig. 5(a) is used for transmission measurements. With this configuration it is possible to measure the absorbance of a catalyst loaded in the transparent Pyrex reactor after bonding, after a reaction has been performed and in situ during a reaction while measuring the activity of the catalysts. In this setup the light illuminates the reactor and the catalyst from the top. The light that is transmitted through the reactor chamber is directed into a detector (a calibrated spectroradiometer, International Light model RPS-900R) by a $45^{\circ}$ silver mirror. The transmitted light is compared with a reference spectrum taken without the catalyst. The light that does not arrive to the detector is assumed to be absorbed. This is only valid if both reflection and scattering are negligible, because this method does not make any distinction between scattered and absorbed light. Therefore, this method is only useful for thin films, where scattering is negligible compared to absorbance. The mirror is only necessary for our particular setup, because the detector could not fit under the reactor.

Reflection measurements are preferable for highly scattering samples, i.e., layers of catalytic nanoparticles in the $\mu \mathrm{m}$ range. In this case, the configuration shown in Fig. 5(b) is used. An integrating sphere is used for this kind of measurements. The integrating sphere (Mikropack ISP-50-8-R-GT, $50 \mathrm{~mm}$ ) used in the experiments presented in Sec. VI C has an external cylindrical shape with a hole of $8 \mathrm{~mm}$ in the bottom part. The reactor with the catalyst is placed against this

side, with the catalyst area aligned with the hole. An optical fiber connected to the top of the sphere illuminates the catalyst. A second optical fiber, connected from the side of the sphere to a detector, collects the diffuse light (the reflected and scattered components) from the sphere. A diffusive mirror is placed under the catalyst to assure that the light that is transmitted through the catalyst or scattered in the forward directions is sent back into the sphere. With this setup it is possible to measure the Kubelka-Munk function of a catalyst after bonding of the reactor at any moment and in particular after a reaction has been performed.

Unlike the transmission mode, with this configuration it is more difficult to measure during a reaction since the sphere cannot be positioned in direct contact with the reactor while this is mounted in the gas manifold block as the latter is a physical obstacle.

In both of the configurations mentioned above the light source used is a $1 \mathrm{~kW}$ Xe-arc source (Newport model 66924) equipped with a water filter to eliminate unwanted longwavelength light.

\section{EXPERIMENTS}

\section{A. Optical transmission of transparent Pyrex $\mu$-reactors}

The optical transmission of the transparent $\mu$-reactor has been investigated with a Cary 1E Spectrophotometer. In Fig. 6 the absorbance obtained with the Cary Spectrometer is plotted for an empty transparent $\mu$-reactor, a Pyrex lid and a transparent $\mu$-reactor loaded with a thin layer of $\mathrm{TiO}_{2}$. An empty beam line (air) has been used as reference for all the measurements. The $\mathrm{TiO}_{2}$ was deposited by spin coating the suspension of w2730x $\mathrm{TiO}_{2}$ from Evonik.

An oscillating behavior overlapping to the absorbance of the Pyrex is observed in the case of an empty $\mu$-reactor. This signal is due to thin-film interference of the light reflected multiple times in the empty $\mu$-reactor chamber. The formula for light interference in the case of a thin gap of air between

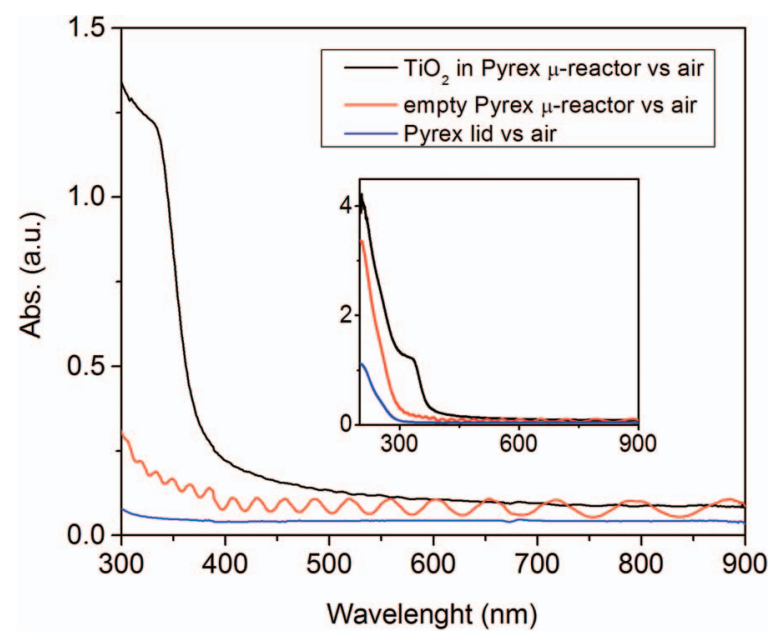

FIG. 6. Absorbance from UV-vis transmission measurements of a Pyrex lid (blue), an empty transparent Pyrex $\mu$-reactor (red), and a transparent $\mu$-reactor loaded with a thin film of $\mathrm{TiO}_{2}$ (black). 

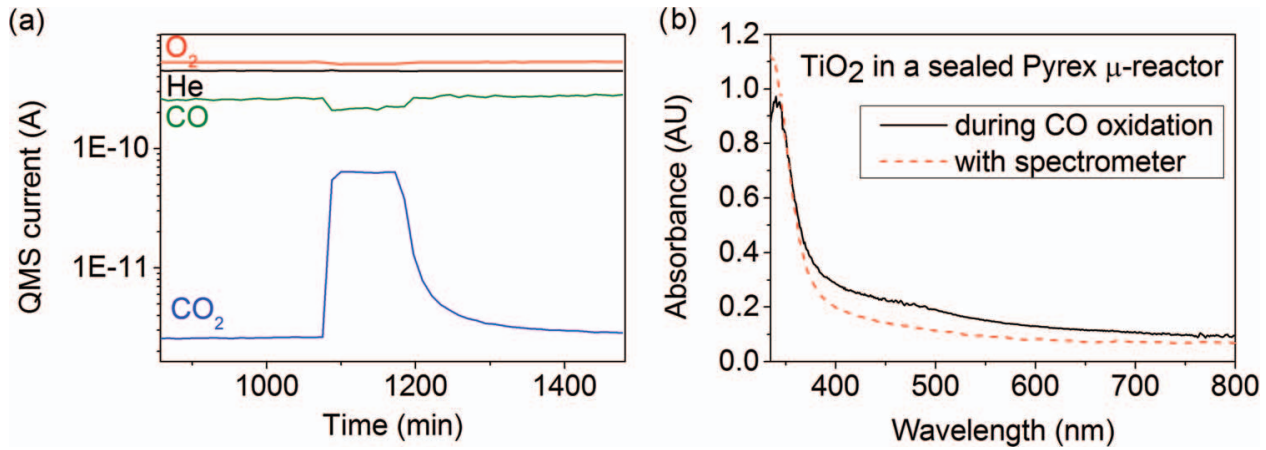

FIG. 7. Photocatalytic $\mathrm{CO}$ oxidation and in situ $\mathrm{UV}$-vis absorbance. The experiments are performed with a transparent $\mu$-reactor loaded with a thin film of $\mathrm{TiO}_{2}$ nanoparticles. The QMS currents for $\mathrm{He}(\mathrm{m} / \mathrm{z}=4), \mathrm{O}_{2}(32), \mathrm{H}_{2} \mathrm{O}(18), \mathrm{CO}_{2}(44)$, and $\mathrm{CO}$ (28) are shown as a function of time (a). The absorbance measurement (solid line) has been taken during photooxidation of $\mathrm{CO}$ to $\mathrm{CO}_{2}$ illuminating the sample with a $1 \mathrm{~kW}$ Xe lamp (b). In (b) the absorbance obtained from a non in situ measurement with a Cary spectrometer is also shown (dashed line).

two flat Pyrex glasses is

$$
2 t=m \frac{\lambda}{2}
$$

where $t$ is the thickness of the air layer, $\lambda$ is the wavelength of light, and $m$ is an integer that is even for constructive and odd for destructive interference. The thickness $t$ can be obtained with this formula from the absorbance of the empty reactor shown in Fig. 6. The value obtained is $\sim 3.76 \mu \mathrm{m}$, in good agreement with the expected value of $3.7 \mu \mathrm{m}$ for the depth of the reactor chamber (the etched depth in the Pyrex is equal to $3.5 \mu \mathrm{m}$ plus the $200 \mathrm{~nm}$ from the etched Si layer). This effect is negligible in the case of the reactor loaded with $\mathrm{TiO}_{2}$, probably due to a small but finite scattering of the nanoparticles that is disturbing the interference. Due to the absence of strong thin film interference, the onset of the absorbance of $\mathrm{TiO}_{2}$ can be estimated from the graph and the value obtained is in good agreement with the literature $(\sim 380 \mathrm{~nm}) .{ }^{11,12}$ When air is used as reference, like in this case, the contributions of the Pyrex lids are not subtracted from the measurements. However, these are only affecting wavelengths shorter than $300 \mathrm{~nm}$, where the Pyrex starts to absorb, while for longer wavelengths the Pyrex is transparent and the reflection is very low (as can be seen in Fig. 6). In any case, a Pyrex lid might be used as reference to further reduce the influence of the surface reflection.

The experiments in this section show that the absorbance of a thin layer of catalyst deposited in a transparent Pyrex reactor can be measured for wavelengths in the visible range and UV wavelengths longer than $300 \mathrm{~nm}(\sim 4.1 \mathrm{eV})$.

\section{B. Photocatalytic activity and in situ UV-vis absorbance: Photocatalytic $\mathrm{CO}$ oxidation with $\mathrm{TiO}_{2}$}

Photocatalytic $\mathrm{CO}$ oxidation was performed as a test reaction combined with in situ UV-vis absorption. A transparent $\mu$-reactor loaded with a thin film of $\mathrm{TiO}_{2}$ (w2730x from Evonik) was used for this test. The reactor was illuminated from the top (with the catalyst on the top Pyrex part), as shown in Fig. 5(a), using an optical fiber connected to a $1 \mathrm{~kW}$ Xe arc lamp (Newport model 66 924). The same light source was used as the probe for the absorbance measurements and the driving light of the photocatalytic reaction.
Helium was used as a feed gas and the reaction was performed under excess of oxygen in the ratio of 3:3:1 of $\mathrm{He}, \mathrm{O}_{2}$, and $\mathrm{CO}$, respectively. The total pressure was set at 1 bar.

The data from the experiments are shown in Fig. 7. Fig. 7(a) shows that the catalyst is active for photocatalytic $\mathrm{CO}$ oxidation, as expected. ${ }^{5}$ Both $\mathrm{CO}$ and $\mathrm{O}_{2}$ are consumed and $\mathrm{CO}_{2}$ evolves when the sample is illuminated. At the same time, the absorbance is recorded (solid line in Fig. 7(b)). The reference spectrum was taken before the start of the oxidation experiments, by placing a Pyrex lid in the manifold block. The onset of the absorption of $\mathrm{TiO}_{2}$ can be estimated from the figure and it is in agreement with the literature. ${ }^{11,12}$ The in situ absorbance shown in Fig. 7(b) is compared with the absorbance of the same reactor measured with a Cary Spectrometer (dashed line). A Pyrex lid was used as reference also with the Cary Spectrometer, but the measurement was performed after the photocatalytic experiment. The comparison shows that the onset of the absorption of the photocatalyst is well reproduced in the measurement obtained using the setup of Fig. 5(a). The slightly higher background for wavelengths longer than $400 \mathrm{~nm}$ in the case of the measurement during the photocatalytic reaction is probably caused by weak light scattering from the edge of the catalyst film or by the scattering and low absorption of the semi-transparent silicon layer at the edge of the reactor chamber. Fig. 7(b) confirms the reliability of the setup for in situ optical transmission measurements as shown in Fig. 5(a).

The experiments of this section are only a proof of concept, because nothing is expected to change in the absorbance during this particular reaction. However, they show the feasibility of photocatalytic activity measurements combined with in situ optical characterization using UV-vis light and transparent Pyrex $\mu$-reactors.

\section{Diffuse reflectance of photocatalysts in transparent Pyrex $\mu$-reactors: $\mathrm{SrTiO}_{3}$ nanoparticles loaded with Pt nanoparticles}

For highly scattering samples it is possible to obtain a better estimate of the absorption of the photocatalysts with the setup illustrated in the schematic of Fig. 5(b). Photocatalysts in the form of nanopowder are often highly scattering. 


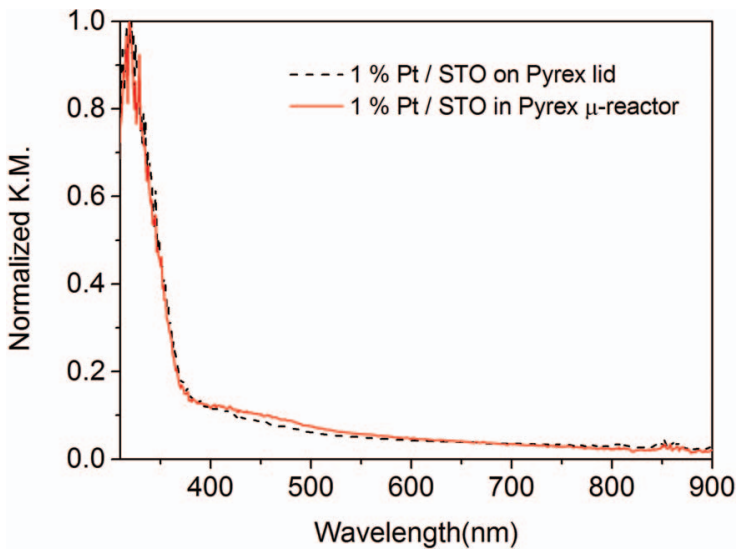

FIG. 8. Diffuse reflectance spectrum of a transparent $\mu$-reactor loaded with $1 \%$ wt $\mathrm{Pt} / \mathrm{SrTiO}_{3}$ (solid line) and $1 \%$ wt $\mathrm{Pt} / \mathrm{SrTiO}_{3}$ on a Pyrex lid (dashed line).

In order to obtain appreciable photocatalytic activity, these photocatalysts are often deposited in the $\mu$-reactor forming a layer of nanoparticles with thickness in the $\mu \mathrm{m}$ range. For this kind of samples, it is possible to obtain Kubelka-Munk functions of the catalysts deposited on a single Pyrex lid. However, it is not possible to measure the reflectance with the catalysts in a sealed silicon based $\mu$-reactor. This measurement is possible with a transparent Pyrex $\mu$-reactor. In Fig. 8 the measurement obtained with $30 \mu \mathrm{g}$ of $\mathrm{SrTiO}_{3}$ (Sigma-Aldrich $\mathrm{SrTiO}_{3}, 99.5 \%$ metal basis, product number 517011) loaded with $1 \%$ wt of Pt nanoparticles in a transparent Pyrex $\mu$-reactor is shown and compared with the one obtained with the same material deposited on a Pyrex lid. The Kubelka-Munk function was obtained using the formula: ${ }^{10}$

$$
F(R)=\frac{K}{S}=\frac{(1-R)^{2}}{2 R}
$$

from the diffuse reflectance measurements. $R$ is the reflectance as measured in the experiments using an integrating sphere and $F(R)$ is the Kubelka-Munk function, often expressed as the ratio of the absorption and scattering coefficients, $K$ and $S$. The $\mathrm{Pt} / \mathrm{SrTiO}_{3}$ system was chosen as an example since $\mathrm{SrTiO}_{3}$ is a well known photocatalyst material, i.e., active for photocatalytic gas phase water splitting when loaded with appropriate cocatalyst ${ }^{13}$ and $\mathrm{Pt}$ nanoparticles are often used as cocatalysts in order to enhance the activity, for example, for the hydrogen evolution reaction. ${ }^{14}$ The procedure followed in order to load the Pt is described in the article by Liu et al. where it is applied to anatase $\mathrm{TiO}_{2} \cdot{ }^{15}$ The Pt is deposited on the $\mathrm{SrTiO}_{3}$ by an impregnation method from an aqueous solution of $\mathrm{H}_{2} \mathrm{PtCl}_{6} \cdot 6 \mathrm{H}_{2} \mathrm{O} .0 .2 \mathrm{~g}$ of $\mathrm{SrTiO}_{3}$ powder was added to the desired amount of $\mathrm{H}_{2} \mathrm{PtCl}_{6} \cdot 6 \mathrm{H}_{2} \mathrm{O}$ solution ( $1 \mathrm{mM}$ Pt solution) in an evaporating dish at $60{ }^{\circ} \mathrm{C}$ above a water bath. During the initial stage of the evaporation the solution was constantly stirred with a magnetic rod and, in the final stage, manual stirring with a glass rod was used. After drying, the powder was collected and heated in air at $180^{\circ} \mathrm{C}$ in an oven for $4 \mathrm{~h}$.

In the optical measurement, a Pyrex lid and a diffusive mirror were used as a reference instead of an empty transparent reactor, in order to avoid the oscillating interference.
The onset of the Kubelka-Munk function is well in agreement with the reported bandgap of $3.2 \mathrm{eV}$ for the $\mathrm{SrTiO}_{3}$, while the Pt nanoparticles probably contribute to the background at longer wavelengths.

This experiment shows that it is possible to perform optical characterization of a sample loaded in a sealed transparent Pyrex $\mu$-reactor not only in transmission but also in diffuse reflection.

The authors believe that the use of the transparent Pyrex $\mu$-reactor is not limited to combine the photocatalytic activity measurements with these techniques and that in the future more optical techniques can in principle be combined with this $\mu$-reactor, i.e., indirect nanoplasmonic sensing, ${ }^{16}$ Raman spectroscopy with probing light in the UV or visible range, ${ }^{17}$ photoluminescence or photoluminescence excitation spectroscopy.

\section{Top and bottom illumination: Photocatalytic ethylene oxidation with P25}

The experiments presented in Secs. VI A-VI C have shown that the transparent Pyrex $\mu$-reactor can be used to combine photocatalytic reactivity measurements and in situ optical characterization. Another important application of these reactors for photocatalytic studies is based on the possibility to illuminate a photocatalyst film or a layer of photocatalytic nanoparticles from two different sides. The two sides of the reactor chamber are different when the material deposited on one side is not enough to occupy the entire height of the reactor chamber and thus the space above the catalyst is filled with gas (see Fig. 3).

In this case, the activity of the film is dictated by the diffusion of the reactant gas through the photocatalyst and the number of photogenerated electron-hole pairs that escape recombination. The effect of this interplay leads to different scenarios in the case that the catalyst is illuminated from the top or from the bottom. ${ }^{8}$

Photocatalytic ethylene oxidation has been chosen as test reaction to investigate the effect of top and bottom illumination. A bottle of compressed air containing $2 \%$ of ethylene (ethylene $2 \%$, oxygen $20.6 \%$, nitrogen $77.4 \%$, class $2.2,1 \mathrm{~A}$ from Air Liquide Denmark) was connected to the setup. A UV-LED with emission centered at $\sim 367 \mathrm{~nm}$ and FWHM of $\sim 9 \mathrm{~nm}$ was used as light source (Hamamatsu model LCL2) mounted with a focusing lens (Hamamatsu L10561-220). This UV-LED is able to produce an average irradiance of $\sim 460 \mathrm{~mW} \mathrm{~cm}^{-2}$ on the sample area (measured using a Thorlabs photodiode, model S120VC). For these experiments the intensity of the UV-LED was set to only $10 \%$ of the max value, due to the high conversion efficiency of the photocatalyst for this reaction.

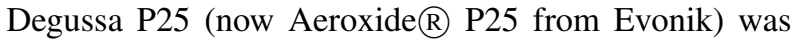
used as photocatalyst, since $\mathrm{TiO}_{2}$ has been reported to show high activity for this reaction. ${ }^{18,19}$ The nanopowder was dispersed in millipore water and sonicated before being drop casted on the Pyrex lid.

The QMS current as a function of time for a Pyrex $\mu$ reactor that was loaded with $6.5 \mu \mathrm{g}$ is shown in Fig. 9. The $\mu$-reactor was illuminated from the top with 6 cycles of $5 \mathrm{~min}$ 


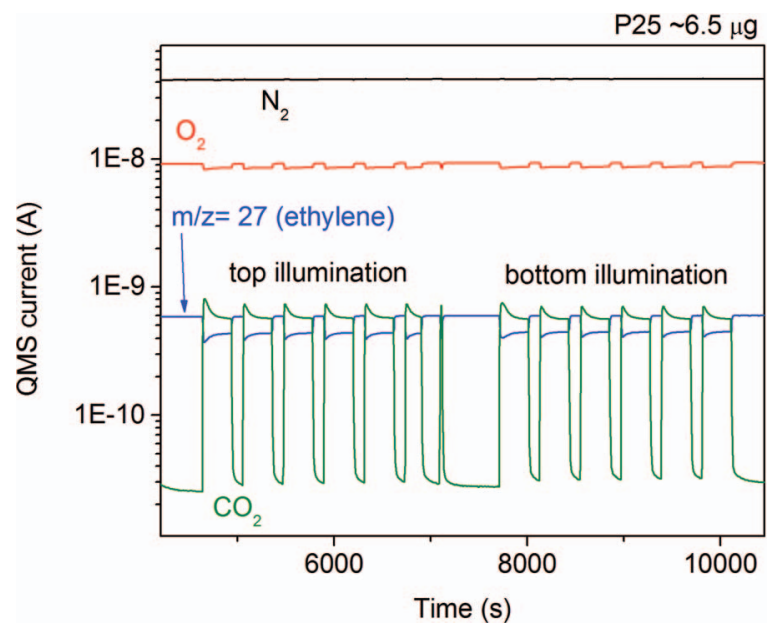

FIG. 9. Photocatalytic ethylene oxidation with top and bottom illumination The experiments are performed with a transparent $\mu$-reactor loaded with $6.5 \mu \mathrm{g}$ of Degussa P25 nanoparticles. The QMS currents for $\mathrm{N}_{2}(\mathrm{~m} / \mathrm{z}=28)$, $\mathrm{O}_{2}$ (32), ethylene (27), and $\mathrm{CO}_{2}$ (44) are shown as a function of time.

of irradiation each (the sixth cycle was interrupted slightly before $5 \mathrm{~min}$ ). In Fig. 9 it can be seen that $\mathrm{CO}_{2}$ is evolved during illumination and $\mathrm{O}_{2}$ and ethylene (monitored at the cracking part at $\mathrm{m} / \mathrm{z}=27$ ) is consumed. The signal of $\mathrm{N}_{2}$ is not affected by illumination, as expected $(\mathrm{m} / \mathrm{z}=28$ is slightly affected as this coincides with ethylene). The sample is clearly active for photocatalytic ethylene oxidation. After the sixth cycle, the UV-LED is moved below the reactor. The sample is illuminated from the bottom with other 6 cycles of $5 \mathrm{~min}$.

The measurements were also performed with four other different transparent Pyrex $\mu$-reactors, each loaded with the same photocatalyst in different amounts: $13 \mu \mathrm{g}, 10 \mu \mathrm{g}, 5 \mu \mathrm{g}$, and $4 \mu \mathrm{g}$. For all the samples tested, the difference between top and bottom illumination was almost zero. Fig. 9 shows the sample where the difference between top and bottom illumination was the highest, $\sim 9 \%$ of the ethylene consumption (estimated from the decrease of $\mathrm{m} / \mathrm{z}=27$ ). The average difference in percentage respect to the ethylene consumption was $4.2 \%$ among all the samples.

Due to low light absorption of the photocatalysts (the sample with the larger amount of catalysts still transmits $28 \%$ of the light at wavelength of $\sim 365 \mathrm{~nm}$, as measured with the Cary spectrophotometer) and probably high diffusivity there is no clear difference in activity for front and back illumination for these samples. A different behavior could, however, be expected for more compact films like those that we have investigated in a previous work, ${ }^{8}$ but that study is beyond the scope of this investigation.

\section{CONCLUSIONS}

A new Pyrex-based $\mu$-reactor is presented in this work. The reactor is composed of two components: a featureless Pyrex lid and a Pyrex reactor chip with a thin polysilicon overlayer. The gas channels and the reactor chamber are etched in the silicon-covered Pyrex chip. The reactor is sealed by anodic bonding of the two Pyrex chips thanks to the thin polysilicon interlayer.

Absorption and diffuse reflectance measurements can be obtained with the photocatalysts deposited inside transparent Pyrex $\mu$-reactors after the reactors have been sealed, and examples with $\mathrm{TiO}_{2}$ and $\mathrm{SrTiO}_{3}$ are reported. Optical characterization using transmitted light is combined with measurements of photocatalytic activity (photocatalytic $\mathrm{CO}$ oxidation with $\mathrm{TiO}_{2}$ ). These experiments prove the possibility to combine in situ optical characterization with photocatalytic activity measurements.

Another application for this kind of reactor is illumination of the photocatalyst film from two different sides where the activity can be measured and compared. An example is presented with photocatalytic ethylene oxidation and P25 nanoparticles. This kind of experiment is interesting for obtaining information on fundamental mechanism of photocatalysis such as gas diffusion in the photocatalyst film.

\section{ACKNOWLEDGMENTS}

Center for Individual Nanoparticle Functionality (CINF) is financed by the Danish National Research Foundation (DNRF54). This project was also funded by "Catalysis for Sustainable Energy" (CASE) research initiative, which is funded by the Danish Ministry of Science, Technology and Innovation.

${ }^{1}$ M. Oelgemöller and O. Shvydkiv, Molecules 16, 7522 (2011).

${ }^{2}$ T. R. Henriksen, J. L. Olsen, P. C. K. Vesborg, I. Chorkendorff, and O. Hansen, Rev. Sci. Instrum. 80, 124101 (2009).

${ }^{3}$ P. C. K. Vesborg, J. L. Olsen, T. R. Henriksen, I. Chorkendorff, and O. Hansen, Rev. Sci. Instrum. 81, 016111 (2010).

${ }^{4}$ P. C. K. Vesborg, S.-I. In, J. L. Olsen, T. R. Henriksen, B. L. Abrams, Y. Hou, A. Kleiman-Shwarsctein, O. Hansen, and I. Chorkendorff, J. Phys. Chem. C 114, 11162 (2010).

${ }^{5}$ P. C. K. Vesborg, J. L. Olsen, T. R. Henriksen, I. Chorkendorff, and O. Hansen, Chem. Eng. J. 160, 738 (2010).

${ }^{6}$ F. Dionigi, P. C. K. Vesborg, T. Pedersen, O. Hansen, S. Dahl, A. Xiong, K. Maeda, K. Domen, and I. Chorkendorff, J. Catal. 292, 26 (2012).

${ }^{7}$ F. Dionigi, P. C. K. Vesborg, T. Pedersen, O. Hansen, S. Dahl, A. Xiong, K. Maeda, K. Domen, and I. Chorkendorff, Energy Environ. Sci. 4, 2937 (2011).

${ }^{8}$ M. G. Nielsen, S.-I. In, P. C. K. Vesborg, T. Pedersen, K. P. Almtoft, I. H. Andersen, O. Hansen, and I. Chorkendorff, J. Catal. 289, 62 (2012).

${ }^{9}$ G. Wallis and D. Pomerantz, J. Appl. Phys. 40, 3946 (1969).

${ }^{10}$ M. P. Fuller and P. R. Griffiths, Anal. Chem. 50, 1906 (1978).

${ }^{11}$ A. Fujishima, X. Zhang, and D. A. Tryk, Surf. Sci. Rep. 63, 515 (2008)

${ }^{12}$ D. Reyes-Coronado, G. Rodríguez-Gattorno, M. E. Espinosa-Pesqueira, C. Cab, R. de Coss, and G. Oskam, Nanotechnology 19, 145605 (2008).

${ }^{13}$ K. Domen, S. Naito, T. Onishi, K. Tamaru, and M. Soma, J. Phys. Chem. 86, 3657 (1982).

${ }^{14}$ A. Kudo and Y. Miseki, Chem. Soc. Rev. 38, 253 (2009).

${ }^{15}$ G. Liu, H. G. Yang, X. Wang, L. Cheng, H. Lu, L. Wang, G. Q. (Max) Lu, and H.-M. Cheng, J. Phys. Chem. C 113, 21784 (2009).

${ }^{16}$ E. M. Larsson, C. Langhammer, I. Zoric, and B. Kasemo, Science 326, 1091 (2009).

${ }^{17}$ F. Fan, Z. Feng, and C. Li, Acc. Chem. Res. 43, 378 (2010).

${ }^{18}$ T. N. Obee and S. O. Hay, Environ. Sci. Technol. 31, 2034 (1997).

${ }^{19}$ D. Park, J. Zhang, K. Ikeue, H. Yamashita, and M. Anpo, J. Catal. 185, 114 (1999). 